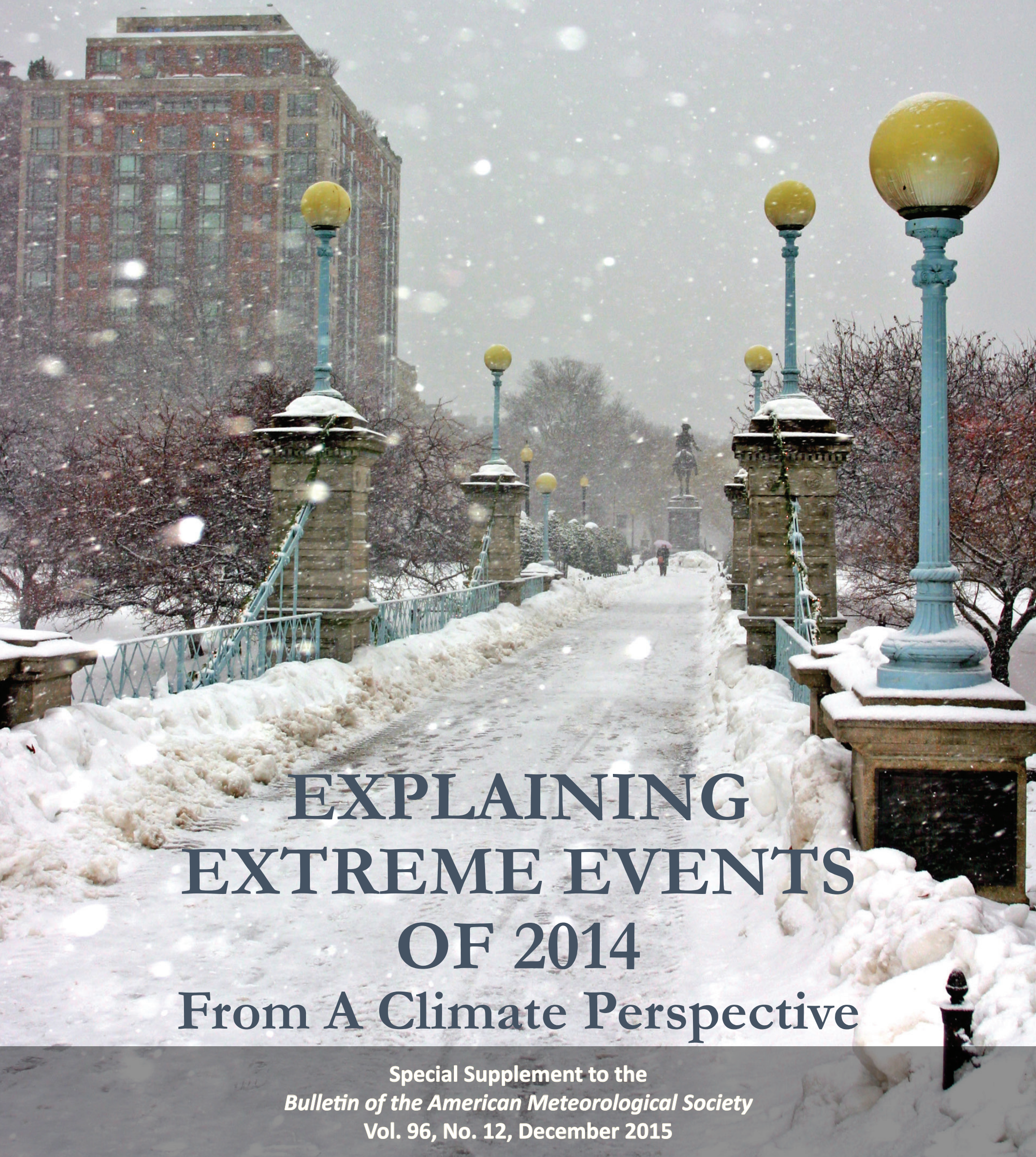




\section{EXPLAINING EXTREME EVENTS OF 20I4 FROM A CLIMATE PERSPECTIVE}

\section{Editors}

Stephanie C. Herring, Martin P. Hoerling, James P. Kossin, Thomas C. Peterson, and Peter A. Stott

Special Supplement to the

Bulletin of the American Meteorological Society

Vol. 96, No. I2, December 2015 
CORRESPONDING EDITOR:

Stephanie C. Herring, PhD

NOAA National Centers for Environmental Information

325 Broadway, E/CC23, Rm IB-I3I

Boulder, CO 80305-3328

E-mail: stephanie.herring@noaa.gov

COVER CREDITS:

Front: (CiStockphotos.com/coleong-Winter snow, Boston, Massachusetts, United States.

BACK: (iStockphotos.com/nathanphoto-Legget, California, United States - August 13, 20I4: CAL FIRE helicopter surveys a part of the Lodge Fire, Mendocino County.

\section{HOW TO CITE THIS DOCUMENT}

Citing the complete report:

Herring, S. C., M. P. Hoerling, J. P. Kossin, T. C. Peterson, and P. A. Stott, Eds., 20I5: Explaining Extreme Events of 2014 from a Climate Perspective. Bull. Amer. Meteor. Soc., 96 (I2), SI-SI72.

Citing a section (example):

Yoon, J. H., S.-Y. S. Wang, R. R. Gillies, L. Hipps, B. Kravitz, and P. J. Rasch, 20I5: Extreme fire season in California: A glimpse into the future? [in "Explaining Extremes of 20I4 from a Climate Perspective”]. Bull. Amer. Meteor. Soc., 96 (I2), S5-S9.

\section{EDITORIAL AND PRODUCTION TEAM}

Riddle, Deborah B., Lead Graphics Production, NOAA/NESDIS National Centers for Environmental Information,

Asheville, NC

Love-Brotak, S. Elizabeth, Graphics Support, NOAA/NESDIS National Centers for Environmental Information,

Asheville, NC

Veasey, Sara W., Visual Communications Team Lead, NOAA/ NESDIS National Centers for Environmental Information, Asheville, NC

Griffin, Jessicca, Graphics Support, Cooperative Institute for Climate and Satellites-NC, North Carolina State University, Asheville, NC

Maycock, Tom, Editorial Support, Cooperative Institute for Climate and Satellites-NC, North Carolina State University, Asheville, NC
Misch, Deborah J., Graphics Support, LMI Consulting, Inc., NOAA/NESDIS National Centers for Environmental Information, Asheville, NC

Osborne, Susan, Editorial Support, LMI Consulting, Inc., NOAA/NESDIS National Centers for Environmental Information, Asheville, NC

Schreck, Carl, Editorial Support, Cooperative Institute for Climate and Satellites-NC, North Carolina State University, and NOAA/NESDIS National Centers for Environmental Information, Asheville, NC

Sprain, Mara, Editorial Support, LAC Group, NOAA/NESDIS National Centers for Environmental Information, Asheville, NC

Young, Teresa, Graphics Support, STG, Inc., NOAA/NESDIS National Centers for Environmental Information, Asheville, NC 
Abstract.

I. Introduction to Explaining Extreme Events of 2014 from a Climate Perspective .................................

2. Extreme Fire Season in California: A Glimpse Into the Future? …………………..................................

3. How Unusual was the Cold Winter of 2013/14 in the Upper Midwest?............................................10

4. Was the Cold Eastern Us Winter of 2014 Due to Increased Variability? .............................................15

5. The 2014 Extreme Flood on the Southeastern Canadian Prairies .................................................... 20

6. Extreme North America Winter Storm Season of 2013/14: Roles of Radiative Forcing and the Global Warming Hiatus.......................................................................................................................... 25

7. Was the Extreme Storm Season in Winter 2013/14 Over the North Atlantic and the United Kingdom Triggered by Changes in the West Pacific Warm Pool?.

8. Factors Other Than Climate Change, Main Drivers of 2014/15 Water Shortage in Southeast Brazil..

9. Causal Influence of Anthropogenic Forcings on the Argentinian Heat Wave of December 2013

10. Extreme Rainfall in the United Kingdom During Winter 2013/14: The Role of Atmospheric Circulation and Climate Change.

II. Hurricane Gonzalo and its Extratropical Transition to a Strong European Storm.............................5I

12. Extreme Fall 2014 Precipitation in the Cévennes Mountains ........................................................ 56

13. Record Annual Mean Warmth Over Europe, the Northeast Pacific, and the Northwest Atlantic During 2014: Assessment of Anthropogenic Influence.

14. The Contribution of Human-Induced Climate Change to the Drought of 2014 in the Southern

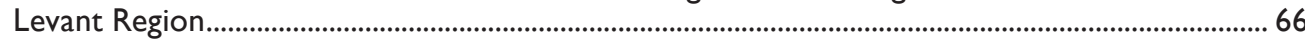

15. Drought in the Middle East and Central-Southwest Asia During Winter 2013/14............................ I

16. Assessing the Contributions of East African and West Pacific Warming to the 2014 Boreal Spring East African Drought

17. The 2014 Drought in the Horn of Africa: Attribution of Meteorological Drivers.

18. The Deadly Himalayan Snowstorm of October 2014: Synoptic Conditions and Associated Trends

19. Anthropogenic Influence on the 2014 Record-Hot Spring in Korea ................................................ 95

20. Human Contribution to the 2014 Record High Sea Surface Temperatures Over the Western Tropical And Northeast Pacific Ocean.

21. The 2014 Hot, Dry Summer in Northeast Asia .............................................................................. 105

22. Role of Anthropogenic Forcing in 2014 Hot Spring in Northern China........................................... III

23. Investigating the Influence of Anthropogenic Forcing and Natural Variability on the 2014 Hawaiian Hurricane Season.

24. Anomalous Tropical Cyclone Activity in the Western North Pacific in August 2014 .................. 120

25. The 2014 Record Dry Spell at Singapore: An Intertropical Convergence Zone (ITCZ) Drought.

26. Trends in High-Daily Precipitation Events in Jakarta and the Flooding of January 2014 ................13।

27. Extreme Rainfall in Early July 2014 in Northland, New Zealand-Was There an Anthropogenic Influence?.

28. Increased Likelihood of Brisbane, Australia, G20 Heat Event Due to Anthropogenic Climate Change.

29. The Contribution of Anthropogenic Forcing to the Adelaide and Melbourne, Australia, Heat Waves of January 2014

30 Contributors to the Record High Temperatures Across Australia in Late Spring 2014 ............... 149

3I. Increased Risk of the 20I4 Australian May Heatwave Due to Anthropogenic Activity................ I54

32. Attribution of Exceptional Mean Sea Level Pressure Anomalies South of Australia in August 2014

33. The 2014 High Record of Antarctic Sea Ice Extent........................................................................ 163

34. Summary and Broader Context....................................................................................................... 168 


\section{ABSTRACT_Stephanie C. Herring, Martin P. Hoerling, James P. Kossin, Thomas C. Peterson, and Peter A. Stott}

Understanding how long-term global change affects the intensity and likelihood of extreme weather events is a frontier science challenge. This fourth edition of explaining extreme events of the previous year (2014) from a climate perspective is the most extensive yet with 33 different research groups exploring the causes of 29 different events that occurred in 2014. A number of this year's studies indicate that human-caused climate change greatly increased the likelihood and intensity for extreme heat waves in 2014 over various regions. For other types of extreme events, such as droughts, heavy rains, and winter storms, a climate change influence was found in some instances and not in others. This year's report also included many different types of extreme events. The tropical cyclones that impacted Hawaii were made more likely due to human-caused climate change. Climate change also decreased the Antarctic sea ice extent in 2014 and increased the strength and likelihood of high sea surface temperatures in both the Atlantic and Pacific Oceans. For western U.S. wildfires, no link to the individual events in 2014 could be detected, but the overall probability of western U.S. wildfires has increased due to human impacts on the climate.
Challenges that attribution assessments face include the often limited observational record and inability of models to reproduce some extreme events well. In general, when attribution assessments fail to find anthropogenic signals this alone does not prove anthropogenic climate change did not influence the event. The failure to find a human fingerprint could be due to insufficient data or poor models and not the absence of anthropogenic effects.

This year researchers also considered other humancaused drivers of extreme events beyond the usual radiative drivers. For example, flooding in the Canadian prairies was found to be more likely because of human land-use changes that affect drainage mechanisms. Similarly, the Jakarta floods may have been compounded by land-use change via urban development and associated land subsidence. These types of mechanical factors reemphasize the various pathways beyond climate change by which human activity can increase regional risk of extreme events. 


\title{
8. FACTORS OTHER THAN CLIMATE CHANGE, MAIN DRIVERS OF 20I4/I5 WATER SHORTAGE IN SOUTHEAST BRAZIL
}

\author{
Friederike E. L. Otto, Caio A. S. Coelho, Andrew King, Erin Coughlan de Perez, Yoshihide Wada, \\ Geert Jan van Oldenborgh, Rein Haarsma, Karsten Haustein, Peter Uhe, Maarten van Aalst, \\ jose Antonio Aravequia, Waldenio Almeida, and Heidi Cullen
}

\begin{abstract}
Southeast Brazil experienced profound water shortages in 20/4//5. Anthropogenic climate change is not found to be a major influence on the hazard, whereas increasing population and water consumption increased vulnerability.
\end{abstract}

Introduction. The southeast region of Brazil (SEB, defined as the area between $15^{\circ}-25^{\circ} \mathrm{S}$ and $40^{\circ}-48^{\circ} \mathrm{W}$; Fig. 8.1a) experienced remarkably dry conditions from January 2014 to February 2015, comprising the 14-month period that includes two rainy seasons investigated here. This region includes São Paulo, Brazil's most populated city, which suffered impacts due to water shortages, and the watersheds and reservoirs feeding the city's water supply system. The wet season occurs during austral summer and the dry season during austral winter. The South Atlantic convergence zone (SACZ) is the main mechanism responsible for the region's austral summer rainfall. During summer 2014, there was a complete absence of SACZ episodes (Coelho et al. 2015). Previous

\begin{abstract}
AfFiliations: Otto, Haustein, AND Uhe-Environmental Change Institute, University of Oxford, Oxford, United Kingdom; Coelho, Aravequia, and Almeida-Center for Weather Forecast and Climate Studies (CPTEC), National Institute for Space Research (INPE), Cachoeira Paulista, São Paulo, Brazil; KINGARC Centre of Excellence for Climate System Science, School of Earth Sciences, University of Melbourne, Melbourne, Victoria, Australia; Coughlan de Perez-Red Cross/Red Crescent Climate Centre, The Hague, Netherlands, and Institute for Environmental Studies (IVM), VU University Amsterdam, Amsterdam, Netherlands, and International Research Institute for Climate and Society, Palisades, New York; WADA-Department of Physical Geography, Utrecht University, Utrecht, Netherlands, and NASA Goddard Institute for Space Studies, New York, New York, and Center for Climate Systems Research, Columbia University, New York, New York; van Oldenborgh and HaARSMARoyal Netherlands Meteorological Institute (KNMI), De Bilt, Netherlands; vaN AALST—Red Cross/Red Crescent Climate Centre, The Hague, Netherlands, and International Research Institute for Climate and Society, Palisades, New York; CulleNClimate Central, Princeton, New Jersey
\end{abstract}

DOI:I0.II75/BAMS-D-I5-00120.I

A supplement to this article is available online $(10.1175$ /BAMS-D-I5-00120.2) major droughts occurred in the region in 1953/54, 1962/63, 1970/71, and 2001. While droughts have very complex criteria, these were all characterized by large rainfall deficits while the effect of the SACZ needs further investigation. The 1953/54 rainfall deficit prompted construction of the largest water supply system (Cantareira) used for São Paulo (Porto et al. 2014). The 2014/15 drought had major impacts in São Paulo due partly to a four-fold population increase since 1960 (Fig. 8.1b). Although new water supply systems were constructed after Cantareira, it is still by far the largest in terms of capacity and number of people supplied (until early 2015) and hence is used as an indicator of the impacts of the SEB drought on water supply. In January 2015, Cantareira, which used to supply 8.8 million people in São Paulo, sank to a water volume of just $5 \%$ of capacity (Fig. $8.1 \mathrm{c}$ ), and currently supplies just 5.3 million people. Other systems (Guarapiranga and Alto Tiete) started to supply the excess population, those previously supplied by Cantareira, after the water crisis was established.

In this analysis, we investigate potential changes in the hydrometeorological hazard, defined by accumulated precipitation and the difference between precipitation and evaporation $(P-E)$ in the SEB region. The true impact, however, is due to a combination of a physical event with vulnerability and exposure, in this case on millions of people in the affected area (Field et al. 2012).

The current drought reflects increasing trends in exposure. São Paulo's population grew by $20 \%$ in the past 20 years. Water use has increased at an even faster rate over the same period (Fig. 8.1b). Vulnerability of water supply systems remains high. Recognizing that water governance is key to reducing vulnerability, 

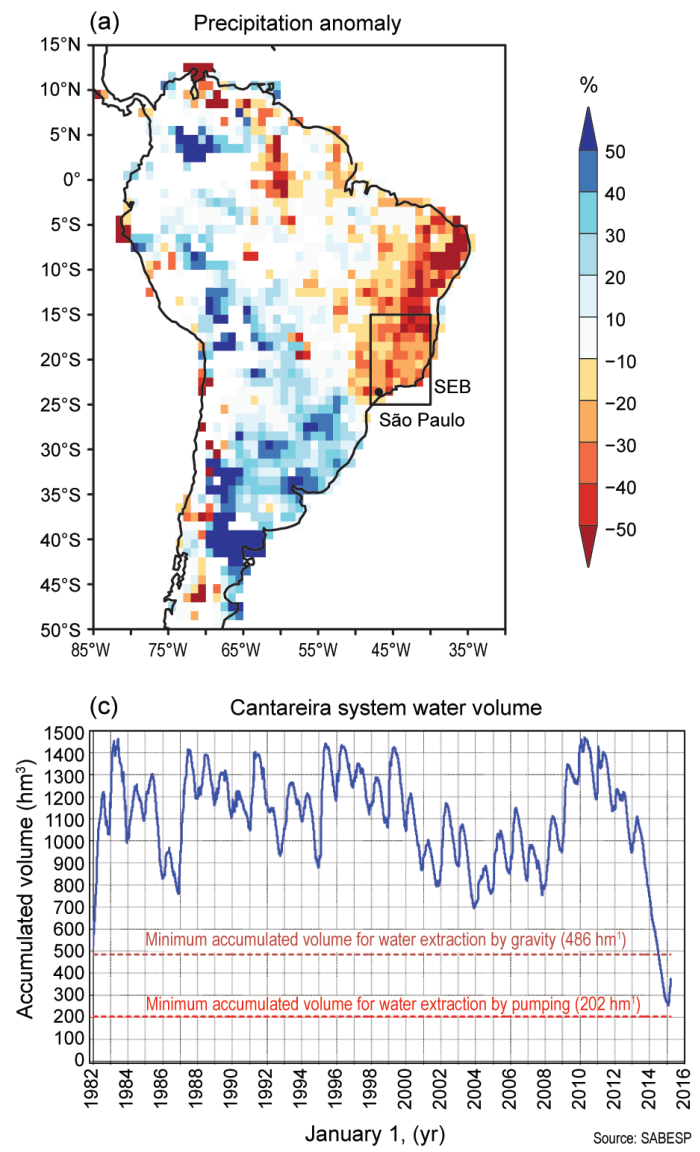

(b) Precipitation and water consumption
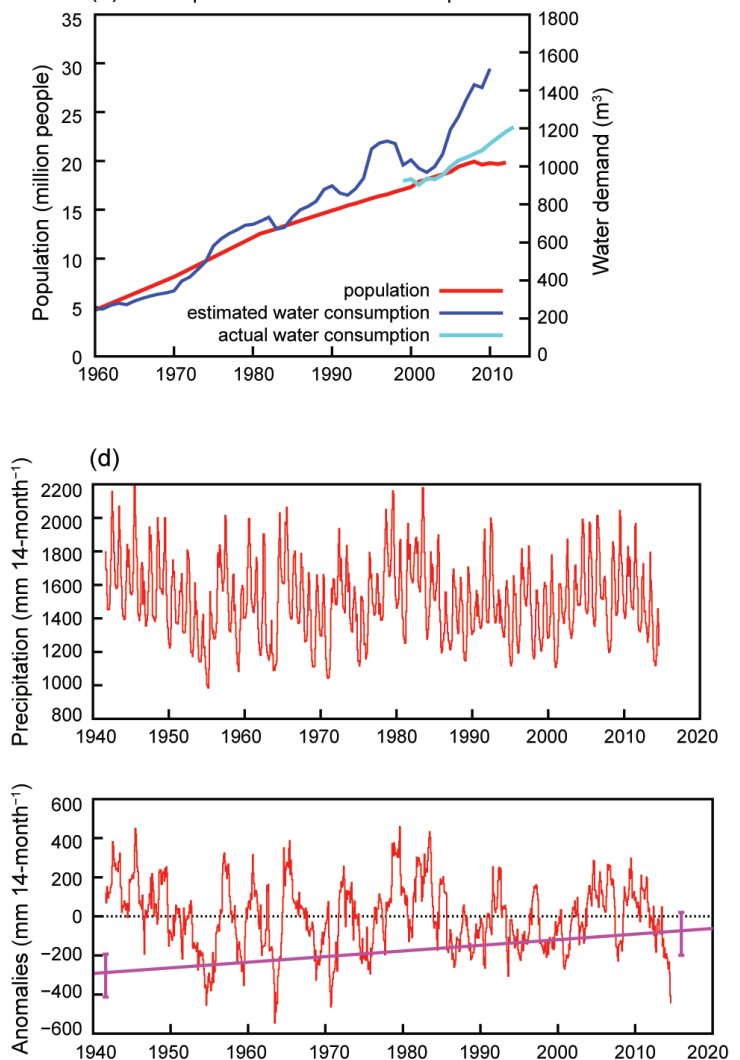

(e) GPCC precipitation SEB area $1941-2013(95 \% \mathrm{Cl})$
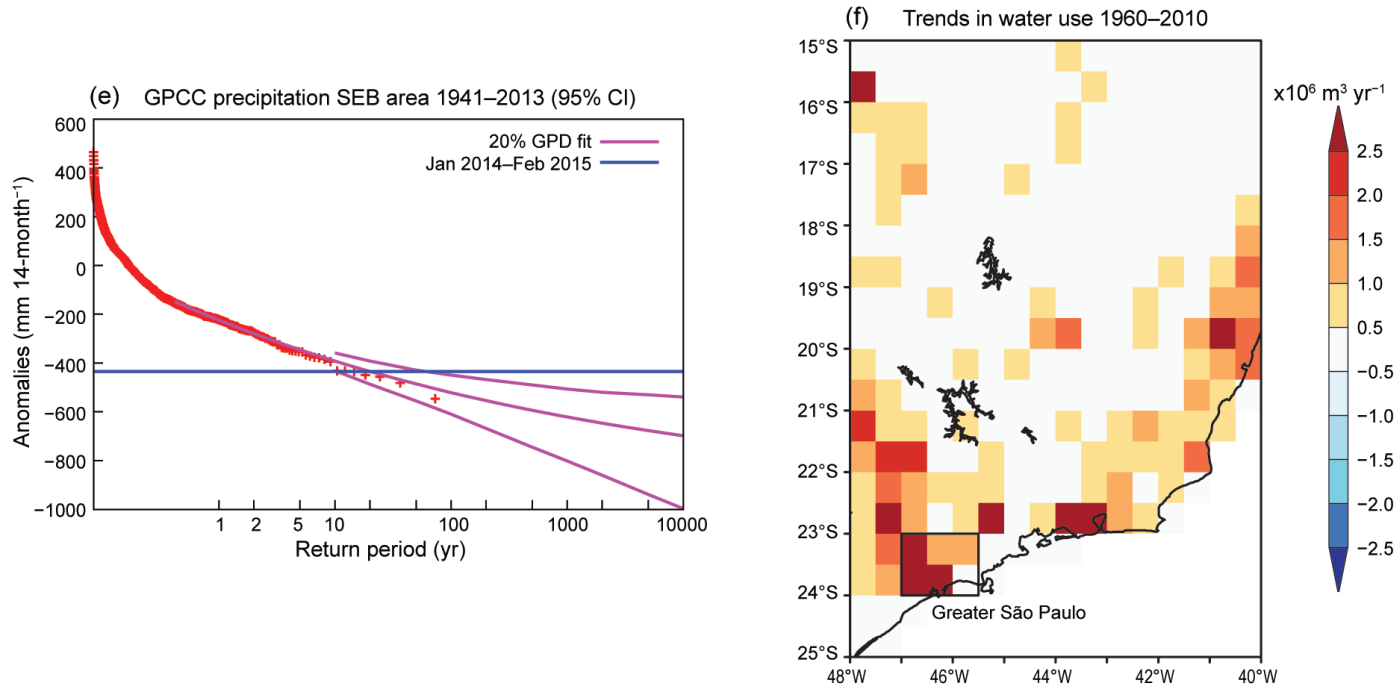

FIG. 8.I. (a) Relative precipitation anomalies in Jan 20I4-Feb 2015 as a percentage of the $194 \mid-2010$ climatology. (Source: GPCC.) (b) São Paulo's metropolitan population (red line) over the period 1960-2012 and estimated (1960-2010, blue) and actual (1999-2013, aqua) water use in Greater São Paulo (defined slightly differently) over the period 1960-2010. Actual water use was obtained from São Paulo state water/waste management company (SABESP). (c) Amount of water stored in the Cantareira water system from completion in Jan 1982 up to Mar 2015. (d, top) 14-month running mean of precipitation in SEB (95\% Cl: $\left.-2.3 \%-1.3 \% 10-y^{-1}\right)$ and (bottom) anomalies. The purple line bottom panel represents the 20th percentile increasing at $0 \%-4 \% 10-y^{-1}$. (e) Fit of the driest $20 \%$ of the 14 -month running precipitation anomalies to a stationary GPD. The horizontal blue line represents the observed 2014/15 precipitation anomaly. (f) Trend in estimated water use in SEB over 1960-2010 in $10^{6} \mathrm{~m}^{3} \mathrm{yr}^{-1}$. (Source: Wada et al. 2014). 
Brazil has advanced decentralization of water management (Engle and Lemos 2010).

Other aspects of vulnerability give a more mixed picture. This drought has not resulted in sustained power outages, a common consequence of water shortages. Similarly, no cholera outbreaks have been reported, reflecting major public health investments (Barrato et al. 2011). Dengue, however, has spiked in São Paulo, with a tripling of cases in 2015 compared with 2014, including several deaths.

Data and methods. Drought can be defined in multiple ways and have multiple drivers (Field et al. 2012). Here we employ a multimethod approach to assess whether and to what extent anthropogenic climate change contributed to the 2014/15 drought event over SEB, using both observations and general circulation model (GCM) simulations of 14-month accumulated precipitation and $P-E$. We chose these measures to robustly assess the combined thermodynamic and dynamic effect of anthropogenic climate change on the drought. Future studies will disentangle these effects and analyze the driving mechanisms (e.g., Coelho et al. 2015). Our methods include: (i) trend and return period estimation for the 2014/15 event based on historical records; (ii) an estimation of the change in return periods of this event by comparing very large ensembles of SST-driven GCM simulations of the current climate with simulations of the climate in a "world that might have been" without anthropogenic greenhouse gas emissions; and (iii) a similar procedure using state-of-the-art coupled climate model simulations (CMIP5; Taylor et al. 2012).

(i) The observational analysis is based on the GPCC-V6 analysis up to 2010 (Global Precipitation Climatology Centre; Schneider et al. 2014), GPCC monitoring analysis 2011-14, and GPCC first guess analysis Jan-Feb2015. The monitoring analysis was adjusted to GPCC-V6 using linear regression on the 1986-2010 overlap period.

Figure 8.1a shows January 2014-February 2015 precipitation anomalies relative to the 1941-2010 mean. Eastern Brazil, including SEB, shows 25\% to $50 \%$ deficits. Figure $8.1 \mathrm{~d}$ shows 14 -month precipitation running means averaged over SEB. No evidence of a trend was found in the mean, whereas dry extremes showed a barely significant decrease up to 2013 (Fig. 8.1d, lower panel). The 2014/15 SEB deficit is similar to previous events, with dry episodes around 1963, 1970, and 1954 more severe than the current episode up to February 2015. Figure 8.1e shows a generalised Pareto distribution (GPD) fit to the driest
$20 \%$ records assuming a stationary distribution. The January 2014-February 2015 deficit $(435 \mathrm{~mm})$ return period is about 20 years (95\% CI: $10-60$ years).

(ii) We use the distributed computing frameworkweather@home-to run the Met Office Hadley Centre atmosphere-only general circulation model HADAM3P (Massey et al. 2015) to simulate precipitation and $P-E$ in two different model ensembles representing: 1) observed climate conditions of 2014/15, and 2) counterfactual conditions under pre-industrial greenhouse gas forcings and 11 different estimates of SSTs without human influence (Schaller et al. 2014). The empirical SEB total precipitation return periods (Fig. 8.2a) show that in this approach dry precipitation extremes have become less likely due to anthropogenic greenhouse gas emissions: what would have been a 1-in-20-year precipitation deficit event like the 14-month 2014/15 event has become approximately a 1-in-30-year event (95\% CI: 0 to 35 years). At the same time there is no detectable change in $P-E$ due to human-induced climate change (Fig. 8.2c) because of an increase in evaporation that cancels the increase in precipitation. The decrease in extreme low precipitation seen in SEB however is not uniform (consistent with observations; see Supplementary Fig. S8.2a) across Brazil as a whole (Fig. 8.2e).

(iii) We use the same approach as described in Lewis and Karoly (2014) and King et al. (2015) to estimate the fraction of attributable risk (FAR; Allen 2003) of precipitation totals below $25 \%, 20 \%, 15 \%$, and $10 \%$ of the 1961-90 average and $P-E$ below 170 $\mathrm{mm}$ (the 10th percentile) in a subset of the CMIP5 ensemble (see supplemental material). In contrast to the weather@home we find an increase in the risk of low precipitation with FARs greater than 0.167 (with $90 \%$ confidence) for the observed accumulated precipitation. However, the null result is confirmed with FARs slightly greater than zero for $P-E$.

Conclusion. While it has been speculated that anthropogenic climate change is a leading driver of the current drought (e.g., Escobar 2015) our multimethod approach finds limited support for this view. Evidence from observations shows large precipitation deficits becoming less common, albeit with large uncertainties. Likewise, large climate model ensembles show a nonsignificant effect of anthropogenic greenhouse gas emissions on the probability of low water availability $(P-E)$. We therefore conclude the hydrometeorological hazard risk has likely not increased due to human-induced greenhouse gas emissions and the large impact of the 2014/15 event (particularly in the 
(a)

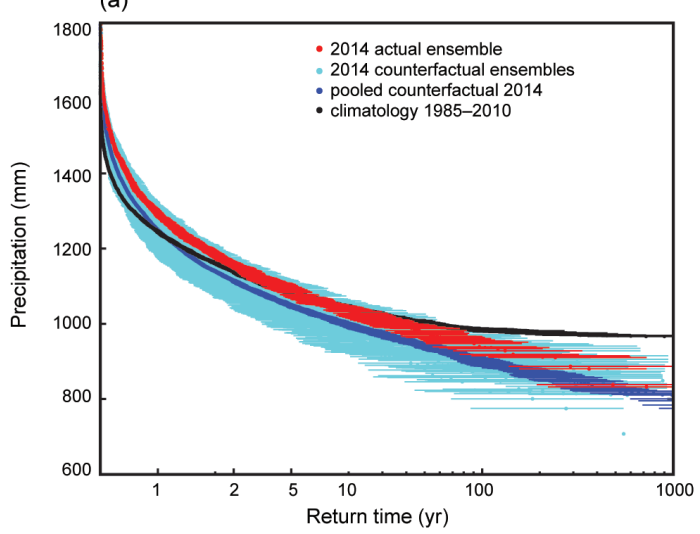

(c)
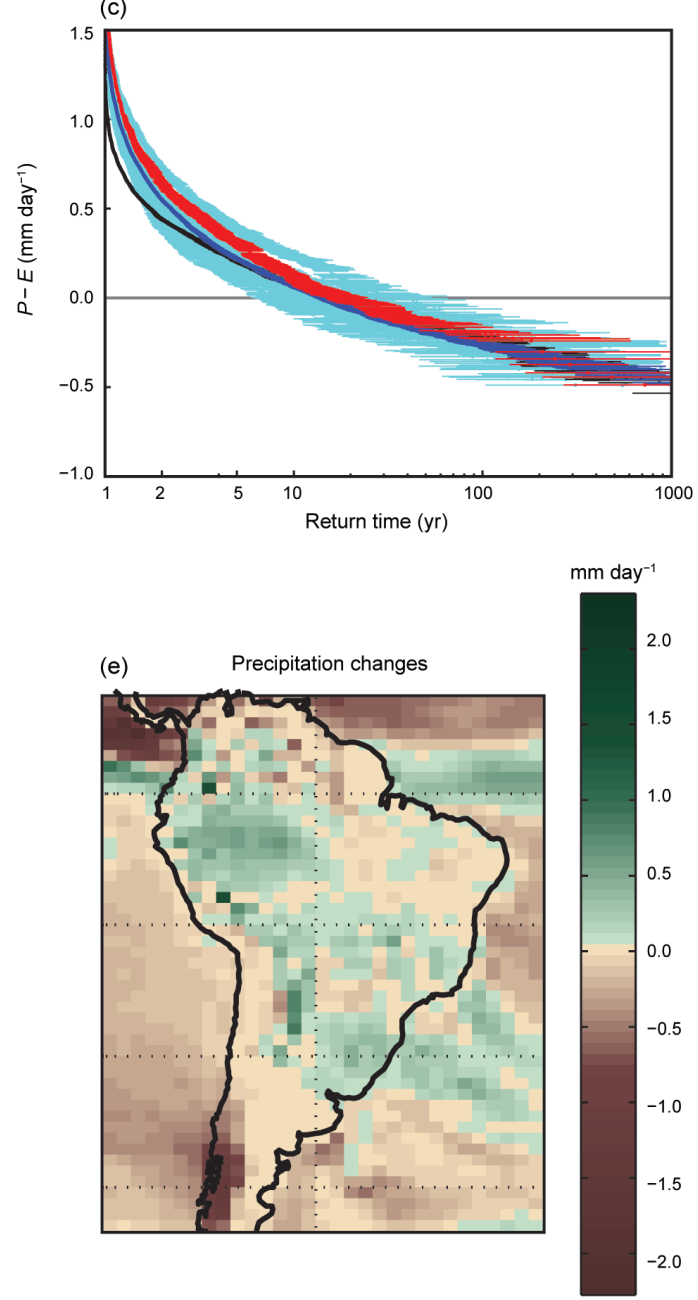

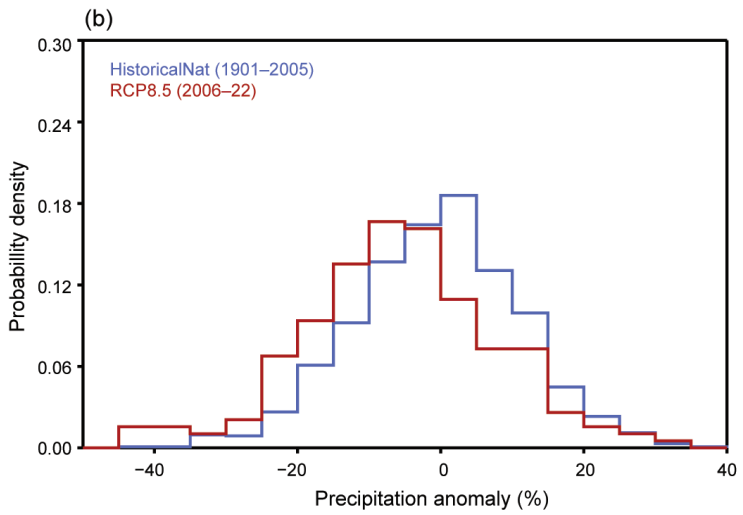

(d)

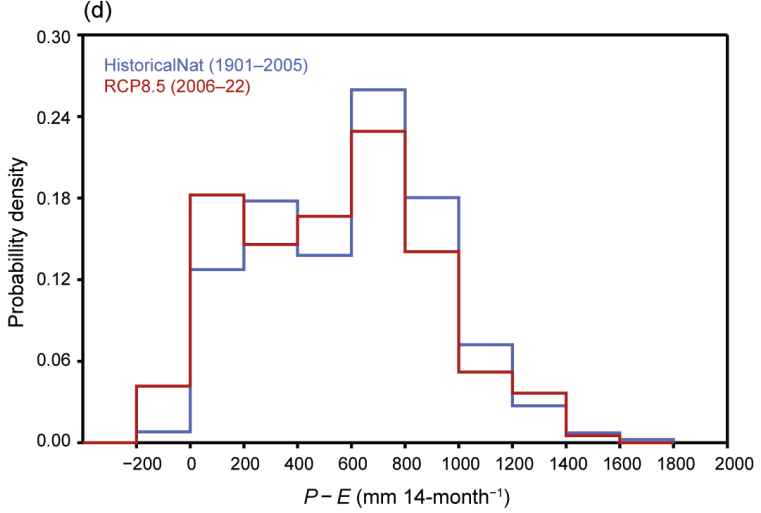

Fig. 8.2. (a) Return periods of total precipitation over SEB from Jan 2014 to Feb 2015 in HadAM3P. (b) Probability density functions (PDF) of 14-month precipitation anomalies in CMIP5 historicalNat and RCP8.5 simulations. (c) Return periods of I4-month mean P-E averaged over SEB in HadAM3P. (d) PDF of I4-month $P-E$ in CMIP5 historicalNat and RCP8.5 simulations. (e) Mean $P-E\left(\mathrm{~mm} \mathrm{day}^{-1}\right)$ in the counterfactual ensemble of Jan 2014 to Feb 2015 subtracted from the actual forcing ensemble for the driest I\% of the simulations. (f) Difference in mean P-E (mm day-1) for RCP8.5 (2006-22) minus historicalNat (190I-2005) for the driest $10 \%$ of the simulations. For all simulations on the left-hand side the single ensemble members have been restarted in Dec 2014 and are thus only continuous in a statistical sense. 
São Paulo region) is more likely driven by water use changes and accelerated population growth.

This does not, however, mean there is no human influence on the hazard itself. We expect (and observe) evaporation to rise due to higher temperatures as a direct consequence of the Clausius-Clapeyron relationship when there is enough water availability. However, this is not the case in droughts where a precipitation deficit over an extended period of time bounds evaporation. Hence the trend in evaporation tends to cancel the trend in dry precipitation extremes, giving a null result in $P-E$ extremes. Overall, our analysis suggests changes in hydrometeorological risk are small while increasing water consumption increases the risk of profound water shortages.

The negative trend in observed dry extremes and large ensemble simulations is in contrast to a positive trend in CMIP5 dry precipitation extremes (Figs. 8.1f, 8.2b). This apparent contradiction could result from the differing physics among the CMIP5 models and weather@home, or from the different underlying assumptions of the different methodologies (e.g., climatological behavior in CMIP5 versus single year simulations using weather@home or SST-forced versus coupled). This highlights the importance of analyzing the same event using multiple methods as a means of better assessing confidence in our results.

Our analysis suggests the specific geographic location of the study area plays an important role in the results as São Paulo sits on the edge of the boundary between decreasing precipitation (to the north) and increasing precipitation (to the south) (Figs. 8.2e,f). Future projections show a continuation of this general pattern, but given the large spread between models, scenarios, and seasons, it is possible the wet-dry boundary will shift leaving São Paulo's precipitation future uncertain (van Oldenborgh et al. 2013). Hence, while the recent drought impacts were most likely not driven by an increase in hydrometeorological hazard, there is a risk that this may not hold in an even warmer world. Future analyses of the dynamical drivers of the hazard might allow this risk to be quantified.

ACKNOWLEDGEMENTS. We thank Antonio Divino Moura and David Karoly for their guidance and input on the manuscript and Dina Sperling and Roop Singh for all their help, our colleagues at the Oxford eResearch Centre and the Met Office Hadley Centre PRECIS team for their support for the application and development of weather@home and all participants in climateprediction.net. The work was supported by the EUCLEIA project funded by the
European Union's Seventh Framework Programme [FP7/2007-2013].

\section{REFERENCES}

Allen, M., 2003: Liability for climate change. Nature, 421, 891-892, doi:10.1038/421891a.

Barreto, M. L., M. G. Teixeira, F. I. Bastos, R. A. A. Ximenes, R. B. Barata, and L. C. Rodrigues, 2011: Successes and failures in the control of infectious diseases in Brazil: Social and environmental context, policies, interventions, and research needs. Lancet, 377, 1877-1889, doi:10.1016/S0140-6736(11)60202-X.

Coelho, C. A. S., and Coauthors, 2015: The 2014 southeast Brazil austral summer drought: Regional scale mechanisms and teleconnections. Climate Dyn., doi:10.1007/s00382-015-2800-1, in press.

Engle, N. L., and M. C. Lemos, 2010: Unpacking governance: Building adaptive capacity to climate change of river basins in Brazil. Global Environ.Change, 20, 4-13, doi:10.1016/j.gloenvcha.2009.07.001.

Escobar, H., 2015: Drought triggers alarms in Brazil's biggest metropolis. Science, 347, 812.

Field, C. B., and Coauthors, 2012: Managing the Risks of Extreme Events and Disasters to Advance Climate Change Adaptation. Cambridge University Press, $582 \mathrm{pp}$.

King, A. D., G. J. van Oldenborgh, D. J. Karoly, S. C. Lewis, and H. Cullen, 2015: Attribution of the record high central England temperature of 2014 to anthropogenic influences. Environ. Res. Lett., 10, 054002, doi:10.1088/1748-9326/10/5/054002.

Lewis, S. C., and D. J. Karoly, 2013: Anthropogenic contributions to Australia's record summer temperatures of 2013. Geophys. Res. Lett., 40, 3705-3709, doi:10.1002/grl.50673.

Massey, N., and Coauthors, 2015: weather@home-development and validation of a very large ensemble modelling system for probabilistic event attribution. Quart. J. Roy. Meteor. Soc., 141, 1528-1545, doi:10.1002/qj.2455.

Porto, R. L., M. F. A. Porto, and M. Palermo, 2014: A ressurreição do volume morto do Sistema Cantareira na Quaresma. Revista DAE, 62 (197), 18-25, doi:10.4322/dae.2014.131.

Schaller, N., F. E. L. Otto, G. J. van Oldenborgh, N. R. Massey, S. Sparrow, and M. R. Allen, 2014: The heavy precipitation event of May-June 2013 in the upper Danube and Elbe basins [in "Explaining Extreme Events of 2013 from a Climate Perspective"]. Bull. Amer. Meteor. Soc., 95 (9), S69-S72. 
Schneider, U., A. Becker, P. Finger, A. Meyer-Christoffer, M. Ziese, and B. Rudolf, 2014: GPCC's new land surface precipitation climatology based on quality-controlled in situ data and its role in quantifying the global water cycle. Theor. Appl. Climatol., 115, 15-40, doi:10.1007 /s00704-013-0860-x.

Taylor, K. E., R. J. Stouffer, and G. A. Meehl, 2012: An overview of CMIP5 and the experiment design. Bull. Amer. Meteor. Soc., 93, 485-498, doi:10.1175 /BAMS-D-11-00094.1.

van Oldenborgh, G. J., M. Collins, J. Arblaster, J. H. Christensen, J. Marotzke, S. B. Power, M. Rummukainen, and T. Zhou, Eds., 2013: Annex I: Atlas of global and regional climate projections. Climate Change 2013: The Physical Science Basis, T. F. Stocker et al., Eds., Cambridge University Press, 1311-1393.

Wada, Y., D. Wisser, and M. F. P. Bierkens, 2014: Global modeling of withdrawal, allocation and consumptive use of surface water and groundwater resources. Earth Syst. Dyn., 5, 15-40, doi:10.5194/esd-5-15-2014. 


\begin{tabular}{|c|c|c|c|}
\hline \multicolumn{4}{|c|}{ ON EVENT STRENGTH † } \\
\hline & INCREASE & DECREASE & NOT FOUND OR UNCERTAIN \\
\hline Heat & $\begin{array}{l}\text { Australia (Ch. 3I) } \\
\text { Europe (Ch. I3) } \\
\text { S. Korea (Ch. 19) }\end{array}$ & & $\begin{array}{l}\text { Australia, Adelaide \& Melbourne } \\
\text { (Ch. 29) } \\
\text { Australia, Brisbane (Ch.28) }\end{array}$ \\
\hline Cold & & Upper Midwest (Ch.3) & \\
\hline $\begin{array}{l}\text { Winter } \\
\text { Storms and } \\
\text { Snow }\end{array}$ & & & $\begin{array}{l}\text { Eastern U.S. (Ch. 4) } \\
\text { N. America (Ch. 6) } \\
\text { N. Atlantic (Ch. 7) }\end{array}$ \\
\hline $\begin{array}{c}\text { Heavy } \\
\text { Precipitation }\end{array}$ & Canada** (Ch. 5) & & $\begin{array}{l}\text { Jakarta**** (Ch. 26) } \\
\text { United Kingdom } * * * *(C h . ~ 10) \\
\text { New Zealand (Ch. 27) }\end{array}$ \\
\hline Drought & $\begin{array}{l}\text { E. Africa (Ch. 16) } \\
\text { E. Africa* (Ch. 17) } \\
\text { S. Levant (Ch. 14) }\end{array}$ & & $\begin{array}{l}\text { Middle East and S.W. Asia } \\
(\text { Ch. I5) } \\
\text { N.E. Asia (Ch. 2I) } \\
\text { Singapore (Ch. 25) }\end{array}$ \\
\hline $\begin{array}{l}\text { Tropical } \\
\text { Cyclones }\end{array}$ & & & $\begin{array}{l}\text { Gonzalo (Ch. II) } \\
\text { W. Pacific (Ch. 24) }\end{array}$ \\
\hline Wildfires & & & California (Ch. 2) \\
\hline $\begin{array}{l}\text { Sea Surface } \\
\text { Temperature }\end{array}$ & $\begin{array}{l}\text { W. Tropical \& N.E. Pacific (Ch. 20) } \\
\text { N.W. Atlantic \& N.E. Pacific (Ch. 13) }\end{array}$ & & \\
\hline $\begin{array}{l}\text { Sea Level } \\
\text { Pressure }\end{array}$ & S. Australia (Ch. 32) & & \\
\hline $\begin{array}{l}\text { Sea Ice } \\
\text { Extent }\end{array}$ & & & Antarctica (Ch. 33) \\
\hline
\end{tabular}

† Papers that did not investigate strength are not listed.

t† Papers that did not investigate likelihood are not listed.

* No influence on the likelihood of low rainfall, but human influences did result in higher temperatures and increased net incoming radiation at the surface over the region most affected by the drought.

** An increase in spring rainfall as well as extensive artificial pond drainage increased the risk of more frequent severe floods from the enhanced rainfall.

*** Evidence for human influence was found for greater risk of UK extreme rainfall during winter 2013/14 with time scales of 10 days

***** The study of Jakarta rainfall event of 2014 found a statistically significant increase in the probability of such rains over the last 115 years, though the study did not establish a cause. 


\title{
ON EVENT LIKELIHOOD ††
}

Argentina (Ch. 9)

Australia (Ch. 30, Ch. 31)

Australia, Adelaide (Ch. 29)

Australia, Brisbane (Ch. 28)

Melbourne, Australia (Ch. 29)

Europe (Ch. 13)

S. Korea (Ch. 19)

China (Ch. 22)

Cold
Winter
Storms and
Snow

Heavy
Precipitation

(a)

N. America (Ch. 6)

S. France (Ch. 12)

Middle East and S.W. Asia (Ch. 15)

Drought

E. Africa (Ch. 16)

S. Levant (Ch. 14)

E. Africa* (Ch. 17)

N.E. Asia (Ch. 2I)

Wildfires

\author{
California (Ch. 2)
}

\section{W. Tropical \& N.E. Pacific}

Sea Surface

Temperature

(Ch. 20)

N.W. Atlantic \& N.E. Pacific (Ch. 13)

Sea Level

Pressure

S. Australia (Ch. 32)

Sea Ice

Extent

.

Antarctica (Ch. 33)

† Papers that did not investigate strength are not listed.

t† Papers that did not investigate likelihood are not listed.

* No influence on the likelihood of low rainfall, but human influences did result in higher temperatures and increased net incoming radiation at the surface over the region most affected by the drought.

** An increase in spring rainfall as well as extensive artificial pond drainage increased the risk of more frequent severe floods from the enhanced rainfall.

*** Evidence for human influence was found for greater risk of UK extreme rainfall during winter 2013/14 with time scales of 10 days

***** The study of Jakarta rainfall event of 2014 found a statistically significant increase in the probability of such rains over the last II5 years, though

the study did not establish a cause. 